\title{
How to Leave Behind What?
}

\section{Outside the Anthropological Machine. Crossing the Human-Animal Divide and Other Exit Strategies. Edited by Chiara Mengozzi. New York-London:} Routledge, 2021. 292 pp.

\section{Gábor Mezei}

Institute of Hungarian Literature and Cultural Studies, Eötvös Loránd University, 1088 Budapest, Múzeum Krt.4/A; mezei.gabor@btk.elte.hu

Containing a direct reference in its title, Outside the Anthropological Machine, to Agamben's rightfully famous book The Open, this edited volume accepts a perspective that does not take for granted a clear distinction between man and animal. In Chiara Mengozzi's editorial introduction, that provides a well-defined conceptual basis and tries to lay the common ground shared by the chapters, she calls our attention to the end of Agamben's book as a kind of starting point to the present collection. It is a vantage point in the sense that according to the authors' intentions formulated in the introduction, the chapters are searching for ways to leave the anthropological machine that serves as a tool to recognize or articulate the human, while and as a result of defining the animal in a deprivative way. Speaking about the animal from this perspective, on the other hand, still does not solve the problem whether there are any ways of separating the human and the non-human.

At the end of Agamben's book, we read that we have to "show the central emptiness, the hiatus that-within man-separates man and animal". ${ }^{1}$ This conclusion, that Agamben considers necessary, and is quoted in the introduction to the present book, is hard to apply as a direction for use, as it is too complicated to interpret in a straightforward manner. Though many of the chapters, as well as the introduction where the terms 'human' and 'non-human' are blended and divided at the same time, ${ }^{2}$ take it into consideration while trying to get closer to the question, there are authors who try to come up with an 'exit strategy' presuming that 'the human-animal divide' is a kind of boundary to 'cross'. The question arises whether

1 Agamben, The Open, 92.

2 Mengozzi, Outside the Anthropological Machine, 3. 
the strategy of 'crossing' is indeed a direction that can be taken if we are still unable to gain access to those boundaries. How far those 'other exit strategies' can reach is another issue that is not involved in Agamben's concept. That is the point where the collection makes a shift from its conceptual basis towards positively stating that the animals' "point of view" can be included "within the orbit of human thought and imagination" (p. 2). Either way, the chapters are pointing at a very important issue that has been addressed by the humanities for decades. Depending on the perspectives from which the interrelations are viewed, the methods the chapters apply are different. Focusing on literature, films, video games or historical documents results in diverse ways out of the anthropological machine, especially because they do not share a common ground concerning the nature and the accessibility of the boundaries between the human and the non-human.

There is one point all the chapters accept as a valid start, and that is the necessity to leave behind the anthropocentric paradigm; while "we need to shed a new light on animals", we also have to „undermine our taken for granted identities" (p. 4). The three sections of the book contain a total of fifteen chapters that are trying to do this in different ways. Part I, entitled 'Playing a Part in the Dramaturgy of the Real': (Hi)story on the Side of Animals, calls our attention to the fact that the lives of animals are not visible in the narratives of humankind, even though they play a decisive role in them. The chapters included in this section are moving towards a history where the non-human can be an agent, where animal lives influence decisive events, and where their perspectives matter. Éric Baratay, in a case study about a giraffe's arrival in France in 1826, shows how the history of animals is always a "human history of animals in which [they] are overlooked as real beings" (p. 28). Emphasizing that it is important "to look at events from the giraffe's perspective", the chapter-as it is often stated in animal studies-shows that it is present in the story reconstructed through historical documents as an agent; then it takes a step forward to prove that the giraffe "needs to be appraised as an individual with its own feature, as a 'person' with its own behaviours, and even as a subject making choices and planning strategies" (p. 31). As Baratay remarks, we are trying to get close to this individuality "through human lenses" (p. 29), which means the human/non-human divide is crossed before it is understood in its uncertainty. A very important observation makes all this even more tangible, highlighting that the sources used say a great deal about these relations. Naturalists who examined the giraffe said "As the animal wouldn't let men touch this part of its body [the head], nothing can be said about it" (p. 34). Consequently, we have to accept that through these human lenses we have a rather limited access to the non-human, unless we try to interpret their role and how they are present in these interactions.

In the next chapter, Violette Poullard also points out that animals do not have a part in historiography, but in her study, attention is "devoted to the physical 
environment of captivity as an indirect way to understand how animals experienced the zoo" (p. 41). As in the giraffe's case, it is a situation where different species unknown to the mostly European public are imported at the beginning of the 20th century. This is a situation that involves not only the interrelations mentioned, but the question of foreignness as well, though based on the example of the London Zoo, not much effort was made in this respect. As the chapter makes it obvious through a highly detailed examination of the history of the zoo, this is mostly because crucial decisions were made about their lives without the animals themselves. In this world, only their resistance makes it possible to "reshape management practices" (p. 52), only in this way can their agency be recognized. Just like in the case of the horse, a historical actor that played a decisive role as an agent of power in the slave-trading worlds and in the contact with Native American peoples. As Rachael L. Pasierowska tells us in the third chapter of Part I, "Indians thought that the horse and its rider was all one animal, for they had never seen horses up to this time" (p. 60). Through the perspective of the Native Americans, the human-nonhuman divide seems nonexistent; a very important scene that could be analyzed in still more detail.

There is another factor we often neglect when dealing with these interrelations, namely the effect of industrialization and the mass-production of meat. Michał Krzykawski in "Re-animalizing Animals, Re-animating Humans" points at a crucial phenomenon that explains why we do not see non-human animals as they are. The reason is that we "pay attention to our pets but [tend] to turn our gaze away from those animals we feed them with or eat ourselves", and that is why we are not seeing "singular animal existences" (p. 74). This perspective raises the question of animals as a question of biopolitics and arrives at a critique of modern animal industry. Krzykawski argues that it is the human perception of animals that has changed; the industrial animal produced by human machines works in a "much more material way" than Agamben's anthropological machine (p. 79). The impossibility of leaving the anthropocentric paradigm behind stems from the fact that we cannot perceive non-human animals we share the same world with, and it will stay like this as long as our present experience is basically unchanged. And it is not only the meat industry and the zoo that come into the picture but also another scene of encounters between human and non-human animals, which is the laboratory and all the animals who are targets and/or victims of experiments. The collection covers this topic in Anita Jarzyna's article about Laika, who is the best-known, symbolic figure of space flights, and who was more like a hero than a victim, playing a role in human history, whose life as a dog stays invisible and becomes a curios element of collective imagination (p. 106). The criticism of the anthropocentric perspective is a core point of the last chapter in the first part of the book, where Chiara Mengozzi, reading Karel Čapek's The War with the Newts, raises a question about the consequences of manipulating non-human beings. She shows how the "end of humankind [...] does not necessarily correspond to the end of the (Hi)story" (p. 126); a conclusion that refers 
back to the entire section where all the chapters are pointing in the direction of one interpretation. Despite the urban presence of the zoo, the operation of laboratories or the meat industry, human animals are not at the peak point of evolution, our history is not the only possible history on our planet.

In Part II, human-animal encounters, that have been touched upon in previous studies, are in the focus. Postcards of zookeepers with animals, museums, arrangements of aquariums try to figure out how these spaces enable or fill with tension the encounters between human and non-human animals. The question arises though whether visitors to the zoo who make contact with the animals by touching them are at the same time "trying to cross, or at least blur, the human-animal line" (p. 132), as Maria P. Gindhart states, if we take into consideration the starting point of the collection reflecting on Agamben while pointing at this divide. I do not think that the concepts of the human and non-human are in focus here. Writing about public aquariums, Quentin Montagne draws our attention to the spectator's experience in different kinds of arrangements from painted underwater scenes to huge buildings where the visitor is "included in an immerse show and is physically engaged" (p. 159). These experiences may say-in a similar way as the previous paper-more about the otherwise highly important history of these institutions than about the human-animal divide, and in this respect the endpoint is the penetration of the aquarium, where "the visitor-diver negates the distance that separates him from the animal" (p. 163). In other words, it is again about the techniques used and how they can generate the illusion of closeness, rather than about understanding the nature of the boundaries and the operation of the anthropological machine.

In addition to literary texts-like the work of late-nineteenth-century writers who challenged human exclusivity, as Eva Voldřichová Beránková discusses through a wide range of examples and historical documents, the collection covers other territories as well. An example is Kari Weil's Flesh, Fur, and Forgetting dealing with Berlinde De Bruyckere and her 2016 installation in the Hauser \& Wirth Gallery in New York. The exhibition, that used remains of animals, for example, life-size horses made from horse skin, fabric, wood, and other materials that were "meant to be a tribute to those horses whose lives were lost during the First World War" (p. 167). Human-animal encounters are touched upon through these mixed techniques - the role of horses and their presence in the ordinary routines of WWI make them inseparable from humans. Horses shaped and determined the outcome of events in the same way as human hands shaped the exhibits. The mutual structure of agency comes to life in these installations; the creation of the horse also involves the creation of the human. Kari Weil refers to this mutuality from a slightly different perspective. The exhibition that deals with the notion how the body keeps score of memories through scars shows that "we must learn to read a horse's skin and become, in turn, 'kinesthetically legible' to the horse" (p. 180), to experience our "shared animal fragility" (p. 181). 
Raising the question whether it is even possible to have an "exclusive focus on animals" (p. 203), Anne Simon points at an insight that has not been emphasized so far in the collection. As she argues in her Literature and Animal Expressiveness: On the Cognitive and Ethical Aspects of Zoopoetics, the question of anthropomorphism should be revoked, because human language is more than "only capable of speaking about mankind" (p. 207). What is more, Simon underlines that the question is not whether we can escape our human skins, because a "human being indeed is not only a human being or is more than what we usually think when we speak of humankind': our teeth and bones are made of minerals; we live because we are in symbiosis with microbes, viruses, bacteria, and because we eat and metabolize other living beings" (p. 208). That is why humans have to stop looking down on animals, as they are all inhabitants of the Earth, biomorphic creatures sharing the same, sometimes corporeal space. What literature can provide, she argues, is the experience that leads us to change our access to the world, as we are in the state of forgetfulness according to the papers of this collection that inform us of how the meat industry, among other things, has changed the way we relate to the non-human.

A perfect example for such an experience is Kári Driscoll's discussion of Franz Kafka's "Josefine, the Singer or the Mouse Folk". The songs of mice that are "inaudible to the human ear" are "syntactically complex", they "consist of several distinct syllables or phrases". This means that the squeaking of the mouse we have access to is obviously just a part of their vocal activities, while on the other hand, we are unable to reach a large part of their communication, their world is closed for us. Kafka's text, that points at the distinction between sound and silence, absence and presence, searches exactly for, or is at least directed towards, the divide between human and non-human, that in this context seems to be a boundary of sonorous qualities. What is even more important in this respect is that it is the biological incapability of the human ear because of which this boundary remains in silence; it is literature and science that can get closer to it, even if the human and the non-human are clearly indivisible. For science, this divide is symbolized in $\mathrm{kHz}$, because the songs of mice are between $30-120 \mathrm{kHz}$ as clarified a citation in Driscoll's paper (p. 216). For literature, this is somewhere between sound and silence, a notion that is very much the basis of literary texts, as words and phrases are made possible by the empty spaces between them. Following Derrida, Driscoll refers to the dream of "rendering audible" the unheard, "the thoughts of the animal itself" (p. 219) and to rethink and even to question the "always-already-human identity of the narrative voice" (p. 221).

Though the angle is slightly different, Jonathan Pollock's From Being a Beast to Becoming-Animal: Literary Experiments in Crossing the Species Divide points in a similar direction, starting from "the endless debate about the impossibility of avoiding anthropocentrism and anthropomorphism when writing about animals" (p. 232). Through Uexküll's concept of the Umwelt, the world or milieu, the chapter raises 
the question whether worlds belonging to different living beings can communicate, whether animals can reach any other Umwelten. The chapter calls our attention to different concepts in this respect, showing that animals communicate in gestures, in their forms and bodily presence, and through the gaze of the other. But on the other hand, as our sensory capacities are different, for a human, being a beast is not possible, as demonstrated by Charles Foster's experiment of trying to become five different animals. There are two other chapters in the section that can be read as evidence that not even technology can compensate for the difference between sensory capacities. Concepción Cortés Zulueta discusses the role of point-of-view shots making non-human animals gazing-subjects through a wide selection of films, trying to operate animal perception while, for example, destabilizing human-animal power relations. In Michael Fuchs's Playing (With) the Non-human: The Animal Avatar in Bear Simulator, video games are in focus as vehicles for the encounter with the animal that "deepens the connection between" (p. 267) the human and the non-human. But the question still remains the same: the difference of perspectives, ways of perception and sensory operations can only be illustrated in these cases, and we cannot forget about the fact that it is not the divide we are facing here, we are just emphasizing, rightfully, that there is a difference. That is why it is the notion of becoming that is in the center of Pollock's paper, a becoming that is happening continuously, not reaching its endpoint. Taking inspiration from Deleuze and Guattari, Pollock is moving towards the insight that "there is no sense in defining bodies at all" (p. 237); bodies as becoming, this way are in parallel with the becoming of words, because words can, as he shows through a poem by Stevie Smith, go through a process of becoming just as living organisms do. The problem of defining bodies - that are, as we have seen, more like the symbioses of microbes, bacteria, viruses, etc.-makes it obvious that the dividing line between human and non-human animals cannot be clearly determined or even crossed, as many of the chapters in the present collection have demonstrated.

\section{Bibliography}

Agamben, Giorgio. The Open. Mand and Animal. Stanford: Stanford University Press, 2004.

Mengozzi, Chiara, ed. Outside the Anthropological Machine. Crossing the HumanAnimal Divide and Other Exit Strategies. New York-London: Routledge, 2021. doi.org/10.4324/9781003049883

(c) 2021 The Author(s). 